\title{
Changes in Leadership: A 20-Year Study of Trends in Tenure of Chairs of Departments of Ophthalmology
}

\author{
George P. Kung, BS ${ }^{1}$ Oscar A. Cruz, MD ${ }^{1}$ Heidi Israel, PhD $^{2}$ \\ ${ }^{1}$ Department of Ophthalmology, Saint Louis University School of \\ Medicine, St. Louis, Missouri \\ Address for correspondence Oscar A. Cruz, MD, Department of \\ Ophthalmology, Saint Louis University School of Medicine, $1755 \mathrm{~S}$ \\ 2 Department of Orthopaedic Surgery, Saint Louis University School of \\ Grand Blvd, St. Louis, MO 63104 (e-mail: oscar.cruz@health.slu.edu). \\ Medicine, St. Louis, Missouri \\ J Acad Ophthalmol 2019;11:e35-e39.
}

\begin{abstract}
Objective This article assesses recent trends in tenure length for chairs of academic departments of ophthalmology.

Materials and Methods This is a cross-sectional study of current chairs from 136 institutions. Questionnaires emailed to ophthalmology chairs assessed duration of tenure and demographics of current and previous chairs. Based off of this data, trends in tenure length, turnover rates, and retention rates were determined.

Results From 1998 to 2018, 255 individuals held the position of chair at 95 academic departments of ophthalmology. Mean tenure length was 17.8 years for chairs whose tenure included 2005, and decreased to 15.2 and 10.4 years for chairs whose tenures included 2010 and 2015, respectively. Mean annual turnover began at $5.3 \%$ in the first 5 years of the study, increasing to $6.5 \%$ in the following 5 years before returning to a baseline of $5.3 \%$ in the past 5 years. An average turnover of $5.2 \%$ was demonstrated during the entire study period. Five-year retention rates for new chairs averaged at

Keywords

- ophthalmology departments

- chair tenure

- department management

- chair turnover $86.2 \%$. Representation of female chairs rose from values of 2.1 and $3.1 \%$ in the beginning of the period to 7.3 and $8.4 \%$ in 2015 and 2016, respectively.

Conclusions The average turnover rate for chairs of ophthalmology has remained stable over the past 20 years, with an observed slight decrease in mean tenure length. This stability is welcomed in the wake of predicted turnover within the field of ophthalmology, but continued assessment and preventative policies should be maintained to continue current trends.
\end{abstract}

As the practice of medicine evolves over time, departments must be prepared to adapt as well. Beyond the original goals of patient care, research, and education, Grigsby et al describes a new set of challenges facing departments: "winning contracts, enhancing revenue, reducing costs, recruiting and managing a diverse workforce, and dealing with consumer satisfaction and marketing."1 As the leaders of these facilities, department chairs bear the largest burden of this responsibility.

received

May 24, 2019

accepted after revision

August 19, 2019
DOI https://doi.org/

10.1055/s-0039-1697964. ISSN 2475-4757.
The process of selecting a department chair that is both capable of meeting current and future challenges is an arduous process for both the institution and the chair him/herself. ${ }^{2}$ In addition, new chairs face the struggle of establishing their own reputation in the department and pursuing change in the bureaucracy of health administration. Thus, with decreasing tenure length, department chairs may be removed prior to enacting lasting change. To ensure that department chairs are
Copyright $\odot 2019$ by Thieme Medical Publishers, Inc., 333 Seventh Avenue, New York, NY 10001, USA. Tel: +1(212) 584-4662.
License terms

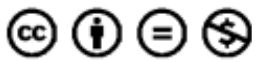


serving long enough to meaningfully contribute to their departments, turnover should be chronically assessed. In other specialties, rates of department chair turnover have been measured previously, providing valuable insight into increasing rates of turnover across facilities. ${ }^{3,4}$

Recent data on turnover, however, has been lacking, particularly in the field of ophthalmology. Previous data reported by Cruz et al demonstrated decreases in mean tenure length and an increased rate of turnover in ophthalmology department chairs from 1983 to $2007 .{ }^{5}$ In a medical environment that has changed greatly in the past 10 years, it is important to examine where the current trends in department chair turnover rate lie and how they have responded to changes in the field.

\section{Materials and Methods}

The Institutional Review Board at Saint Louis University ruled that approval was not required for this study. Data analysis and confirmation were conducted in three stages.

First, data pertaining to the 136 member institutions listed on the Association of University Professors of Ophthalmology (AUPO) Web site as of March 2018 were collected from publicly available resources. These sources included online news articles, department Web sites, and curriculum vitae.

Points collected included year of appointment, year tenure ended, gender, and status as an interim or permanent chair for all chairs at each institution over a 20-year period (1998-2018). Additional data regarding the subspecialties, and endowed chair status, and department versus division status were collected in regard to the current chairs. This collected data was then compiled into a survey-style format individualized for each institution.

In the second stage, chairs and chair administrators were contacted directly through email with a link to the individualized survey containing the precompiled data. Qualtrics survey software was utilized to design and distribute the questionnaire. Each chair or administrator was then asked to confirm or correct the data and add any missing information for the leadership at their institution for the 20-year duration of the study. Unresponsive institutions were followed up via phone and email. To focus on trends in departments of ophthalmology, data from divisions as well as from military-affiliated and Canadian institutions were not included in this study. From the remaining departments, institutions that held departmental status for greater than $85 \%$ of the study period were included in the data set. Data from institutions whose chair history for the duration of the study could be found publicly online were included in this study. Departments whose history could not be attained via public resources or through direct correspondence were not included in the study.

A 20-year timeframe from 1998 to 2018 was selected to allow for adequate assessment of long-term trends in tenure length, turnover rates, and retention rates over time. To calculate tenure length, the number of full calendar years completed by a chair was utilized. Annual turnover rate was defined as the percentage of new chair positions that became available each year. Retention rate for new chairs was calculated as the percentage of new chairs per year that remained in their position for at least 5 years. Interim chairs were defined as individuals who occupied the chair position between the tenures of permanent chairs.

Data analysis was performed by aggregating survey responses into a spreadsheet and rechecking collected data for inconsistencies in the third stage. To protect the confidentiality of the survey participants, institutions and individuals were assigned numerical values. Statistics were calculated and checked for accuracy, with further analysis performed by an independent statistician utilizing SPSS software.

\section{Results}

Of the 136 total AUPO institutions as of March 2018, 9 divisions, 5 military-affiliated institutions, 7 Canadian institutions, and 6 institutions that did not hold departmental status for greater than $85 \%$ of the study duration were identified. Data from these institutions were excluded from the study. Valid data points were ultimately gathered from 95 of 109 departments. Of the 255 individuals who served in the chair position from 1998 to 2018, 50 individuals served as interim chair (19.6\%), with 13 of those individuals moving on to serve as a permanent chair from their interim position. Each department had 2.7 chairs during the study period on average, ranging from 1 to 7 chairs overall. Eleven women served as permanent department chairs and 2 served as interim chairs in the study period. Numbers of female chairs remained stable between $2(2.1 \%)$ and 3 (3.1\%) in the first 16 years of the study, but began to increase in 2014 to highs of 7 (7.3\%), 8 (8.4\%), and $8(8.4 \%)$ in 2015, 2016, and 2017, respectively. Fifty-seven current chairs held endowed positions. The most common primary subspecialties were cornea $(27 \%)$, retina $(23 \%)$, and glaucoma (21\%) (-Table 1 ).

Mean tenure length was calculated from the tenures of permanent chairs serving in each year, excluding tenures of currently seated chairs. Mean tenure length was 16.6 years (standard error of the mean $[\mathrm{SEM}] \pm 0.98$ ) for chairs whose tenure included $2000,17.8$ years $(S E M \pm 1.07$ ) for those whose

Table 1 Primary subspecialty training of current chairs of ophthalmology and percentages of each subspecialty

\begin{tabular}{|l|l|l|}
\hline Primary subspecialty & $\begin{array}{l}\text { Number } \\
\text { of chairs }\end{array}$ & \% Total \\
\hline Cornea & 26 & 27.4 \\
\hline Retina & 22 & 23.2 \\
\hline Glaucoma & 20 & 21.1 \\
\hline Pediatric ophthalmology & 8 & 8.4 \\
\hline Oculoplastics & 6 & 6.3 \\
\hline Neuro-ophthalmology & 5 & 5.3 \\
\hline Comprehensive ophthalmology & 2 & 2.1 \\
\hline Ocular pathology & 2 & 2.1 \\
\hline Anterior segment surgery & 1 & 1.1 \\
\hline Research & 1 & 1.1 \\
\hline Uveitis & 1 & 1.1 \\
\hline
\end{tabular}




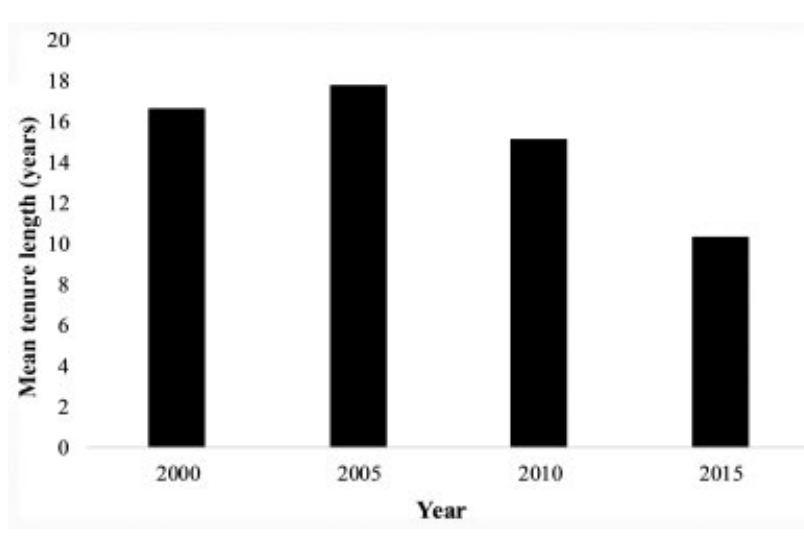

Fig. 1 Bar graph showing the mean tenure lengths of chairs whose tenures included the years 2000, 2005, 2010, and 2015.

tenure included 2005, 15.2 years $(S E M \pm 1.23$ ) for those whose tenure included 2010 , and 10.4 years $(S E M \pm 2.15)$ for those whose tenure included 2015 (-Fig. 1). Eight individuals served the entire study period (1998-2018).

The mean annual turnover was $5.3 \%$ for the first 5 years of the study (1998-2002). This increased to $6.5 \%$ in the 2003 to 2007 period and decreased to $3.8 \%$ from 2008 to 2012 prior to returning to a value of $5.3 \%$ in the 2013 to 2017 period (- Fig. 2). Annual turnover rates ranged from a low of $0 \%$ in 1999 to a high of $9.5 \%$ in 2002 and in 2005 . The mean annual turnover for the entire duration of the study period was $5.2 \%(\mathrm{SEM} \pm 0.54 \%)$.

The average 5-year retention rate for new chairs appointed in the 1999 to 2013 period was $86.2 \%$ and ranged from a low of $50 \%$ in 1999 to a high of $100 \%$ at multiple points in the study range (2001, 2002, 2003, 2005, 2006, 2008, 2010, 2011) (-Fig. 3).

\section{Discussion}

The results of this investigation demonstrate relative stability in terms of retention and turnover within chairs of U.S. academic departments of ophthalmology. In the 1983 to
2007 period examined previously, ${ }^{5}$ turnover rates were trending upward and retention rates were trending downward over time. These trends were concerning owing to the potential impact that increased chair turnover has on the finances and relative stability within a department. ${ }^{6}$ Turnover rates in the 1983 to 2007 period fell within a range of 4 to $8 \%$, with an average turnover rate of $6.4 \%$ in academic departments of ophthalmology. Compared with the current study's range of 0 to $9.5 \%$ for 1998 to 2017 and an average turnover rate of $5.21 \%$ $(\mathrm{SEM} \pm 0.54 \%)$, turnover rates seem to be remaining relatively stable.

In a similar fashion, the range of retention rates expanded to 50 to $100 \%$ in the 1999 to 2013 time period compared with the 71 to $100 \%$ range found in the 1983 to 2003 time period previously examined. ${ }^{5}$ This increase in variation can likely be attributed to the small sample size of new chairs that are appointed each year. Despite this change, the average 5-year retention rate was almost identical (86.2\% in the 1999-2013 period vs. $86 \%$ in the $1983-2003$ period).

Stability within the chairperson position is rather surprising given the increasing burden placed on academic departments in the past 10 years. Possible stressors include implementation of new policies to address mandated electronic health records and the Health Insurance Portability and Accountability Act compliance in addition to tighter budget restrictions secondary to decreased reimbursements. The expected response to these challenges would be an increased change in leadership; however, the general trends in turnover and retention found in this study seem to indicate the opposite. The reason for this stability is unclear, but it may be associated with an increased awareness of trends in turnover and isolated practices to address it.

There has been an increased interest in recent years in the trends of and factors contributing to increased turnover within departments. ${ }^{7,8}$ Thus, possible explanations for stable rates of turnover in this study may be secondary to increased awareness of suggested guidelines meant to address this issue. Conflicts between a new physician's expectations and the culture of the

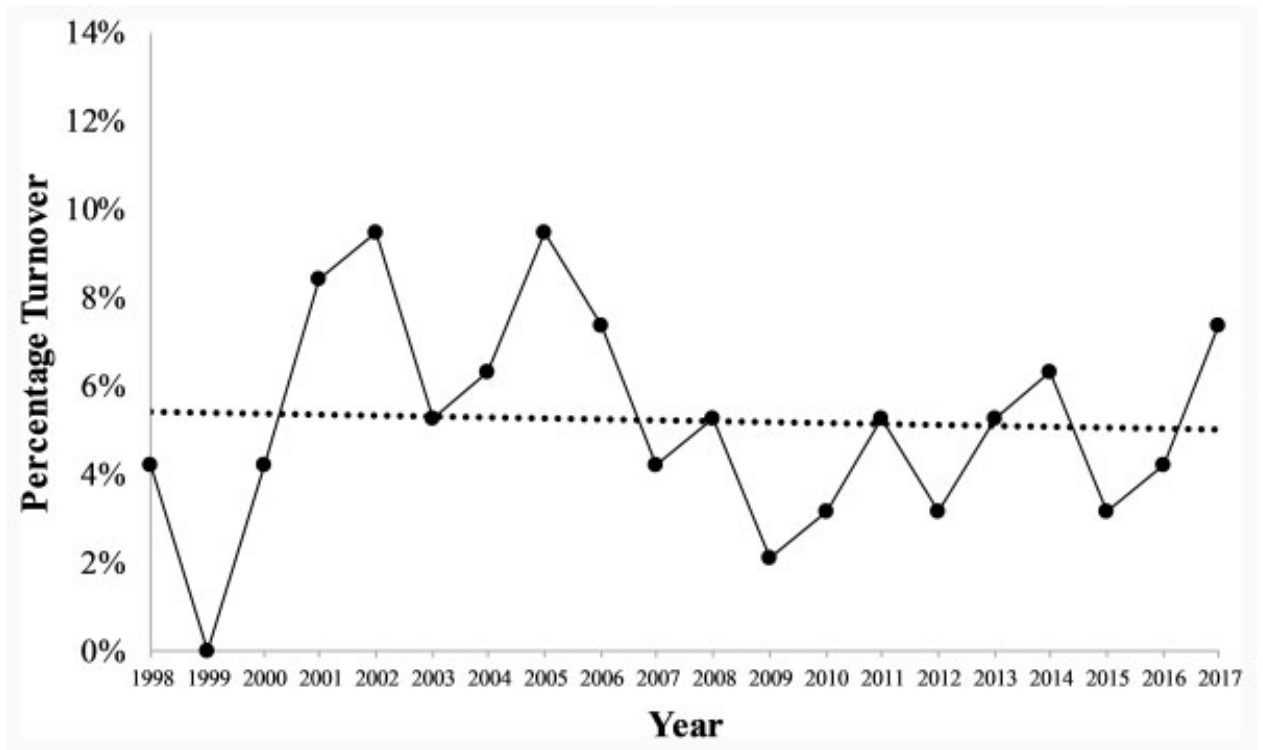

Fig. 2 Graph demonstrating annual turnover rates of academic chairs in ophthalmology between 1998 and 2017. 


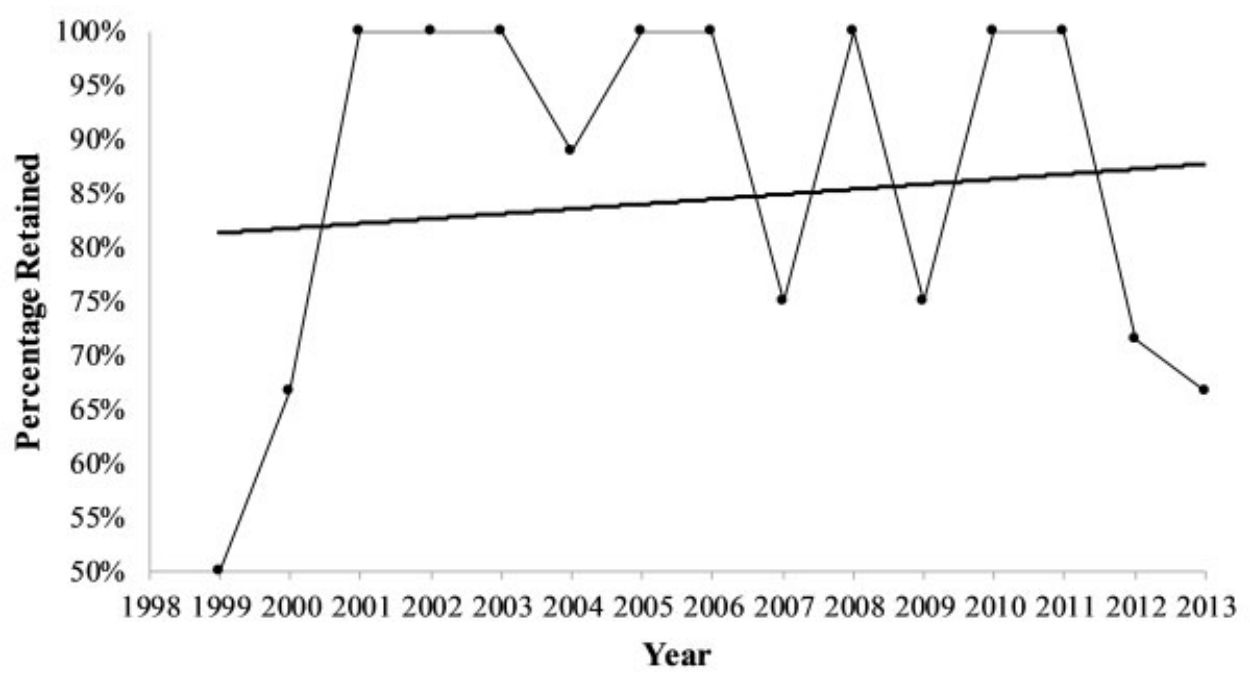

Fig. 3 Graph demonstrating 5-year retention rates of chairs who began their tenure each year beginning 1999 through 2013.

department have been identified as a potential contributor to increased turnover in physicians in nonleadership positions. ${ }^{6}$ Thus, it is possible that this may contribute to turnover at institutions that source new chairs from outside hires. To mitigate these differences, policies such as succession plans and transitional training periods have been proposed to better prepare chairs to adapt to their new leadership roles. ${ }^{9}$ Mentorship also can ease this transition period, and has been implemented within ophthalmology as of late. The AUPO has established a mentoring program as well as an annual training session offered to new chairs to share advice on managing the new challenges that one faces as a chair.

The proportion of female chairs in the study period is noteworthy as it reflects a gradual change in the demographic makeup of chairs of ophthalmology. The current percentage of female chairs (8.4\% in 2017) is an increase compared with previous percentages of $5.1 \%$ and $3.7 \%$ in 2003 and 2007, respectively. While increased numbers of female chairs are an improvement, they have not caught up with the current demographics of the field. Numbers of female residents and practicing ophthalmologists have steadily increased over the past two decades, rising to levels of 44.3 and $22.7 \%$ in 2014 , respectively. ${ }^{10}$ Given the mean tenure length of 10.4 years found in chairs whose tenure included 2015, it is possible that tenure length is one of many factors that makes it challenging for rapid demographic change. These findings indicate that while more women are getting involved in leadership, their rate of growth may remain limited by the gradual nature of change within the path to leadership.

A potential limitation of this study is the belief that turnover is inherently detrimental to departmental function. New chairs may bring in different ideas and skills to the leadership that can greatly benefit an adapting department. However, increased turnover within department faculty has been found to have tangible financial costs, which likely have detrimental effects on departmental function. ${ }^{11}$ No correlation between departmental ranking and chair turnover was found in the previous iteration of this study, but future investigations may better reveal the relationship between turnover and departmental function if other measurements of productivity are examined. ${ }^{5}$ Given the survey format of the study, the data are subject to selfreporting error. To minimize this source of error, chair demographics and timelines were first collected from online resources prior to survey distribution. This process allowed for the initial data to be verified prior to correction by the respective institution in the survey distribution. However, for institutions where online data was unavailable to verify survey responses, potential errors in reporting are possible. Other possible sources of error may stem from institutions whose data was not included either due to lack of survey response or failure to meet inclusion criteria. The inclusion criteria largely focused on identifying departments of ophthalmology in the United States, limiting input from divisions and Canadian institutions which are under different regulatory burdens, and thus, require different management. As a result, the conclusions from this study are likely to be more representative of trends within U.S. departments rather than of all North American institutions of ophthalmology. In addition, institutions that are undergoing increased turnover may have decreased time and/or interest in participating in a survey investigating their leadership trends. Conversely, institutions that are operating comfortably with decreased turnover may have more time and/or interest in responding to this survey. Together, these effects could skew the overall trends toward greater reported stability.

Overall, the results from this study indicate relative consistency in an ever-evolving field. As increasing pressures are placed on departments to perform effectively, departments must continuously assess the effects that these burdens place on staff, particularly those in positions of leadership. By continuing practices that ease instability in transitional periods, departments can ensure that leaders are capable of enacting lasting change.

\section{Conflict of Interest}

None declared. 


\section{References}

1 Grigsby RK, Hefner DS, Souba WW, Kirch DG. The future-oriented department chair. Acad Med 2004;79(06):571-577

2 Grigsby RK, Aber RC, Quillen DA. Commentary: Interim leadership of academic departments at U.S. medical schools. Acad Med 2009; 84(10):1328-1329

3 Stapleton FB, Jones D, Fiser DH. Leadership trends in academic pediatric departments. Pediatrics 2005;116(02):342-344

4 Rayburn WF, Schrader RM, Cain JM, Artal R, Anderson GD, Merkatz IR. Tenure of academic chairs in obstetrics and gynecology: a 25-year perspective. Obstet Gynecol 2006;108(05): 1217-1221

5 Cruz OA, Johnson NB, Thomas SM. Twenty-five years of leadership: a look at trends in tenure and appointments of chairs of ophthalmology. Ophthalmology 2009;116(04):807-811
6 Misra-Hebert AD, Kay R, Stoller JK. A review of physician turnover: rates, causes, and consequences. Am J Med Qual 2004;19(02):56-66

7 Rayburn WF, Alexander H, Lang J, Scott JL. First-time department chairs at U.S. medical schools: a 29-year perspective on recruitment and retention. Acad Med 2009;84(10):1336-1341

8 Kastor JA. Chair of a department of medicine: now a different job. Acad Med 2013;88(07):912-913

9 Rayburn W, Grigsby K, Brubaker L. The strategic value of succession planning for department chairs. Acad Med 2016;91(04):465-468

10 Xierali IM, Nivet MA, Wilson MR. Current and future status of diversity in ophthalmologist workforce. JAMA Ophthalmol 2016; 134(09):1016-1023

11 Schloss EP, Flanagan DM, Culler CL, Wright AL. Some hidden costs of faculty turnover in clinical departments in one academic medical center. Acad Med 2009;84(01):32-36 